\title{
Environmental Performance Index: Regional Aspect
}

\author{
Sergey Bereznev ${ }^{1, *}$, Olga Zonova ${ }^{1}$, and Evdokiya Kulpina ${ }^{1}$ \\ ${ }^{1}$ T.F. Gorbachev Kuzbass State Technical University, 650000, 28 Vesennyaya street, Kemerovo, \\ Russia
}

\begin{abstract}
The methodology of calculation of environmental performance index is considered in the article. The necessity of assessing the environmental efficiency index at the regional level in connection with which the authors attempted to adapt the indicators is proved; the recommendations on improving the national system of environmental indicators for the purpose of maximum correlation with the indicators of the environmental performance index are given.
\end{abstract}

\section{Introduction}

The methodical approaches to measuring and assessing the consequences of human relationships with nature are in the process of improvement. In 1993, the Statistical Division of the UN Secretariat proposed the introduction of the system of environmental and economic accounting with the aim of taking the environmental factor into account in national statistics of different countries, allowing to compare flows related to environmentally exploitive and environmental activities [1, 2]. In 2001, the scientists of Columbia and Yale universities in the framework of the sustainable development assessment proposed the index of environmental sustainability, suggesting the aggregation based on the average arithmetic of 76 indicators [3]. This index allows the inter-country comparing of the environmental sustainability level, assessing the environmental policy results, identifying the countries that are facing the environmental crisis. In addition, the index makes it possible to make more informed decisions based on analytical and quantitative data. The disadvantage of the proposed approach is the large number of evaluation parameters, which makes its practical application difficult. In addition, a number of researchers realized that it is necessary to measure the environmental performance rather than environmental sustainability $[4,5]$.

\section{Materials and Methods}

In order to level the deficiencies in the calculation of the environmental sustainability index in 2006, the Yale University scientists suggested using the Environmental Performance Index (EPI). It is an integrated comparative measure of the success of the state's

\footnotetext{
*Corresponding author: tyulenevaea@kuzstu.ru
} 
environmental policy throughout the world and measures its achievements in terms of the state of the environment and the management of natural resources. The system of indicators on the basis of which the index of environmental performance is built is optimized and amounts to about 22 indicators reflecting various aspects of the state of the environment, in particular, the viability of its environmental systems and the state of human health.

The system of EPI indicators is in continuous development, while not only the system of indicators but also the me-thodology of calculation of the index itself is enduring the change [6]. The foregoing allows concluding that it is im-possible to assess the development of the state in dynamics, which is the limitation of its practical applicability.

In addition, the relevance of the research topic is due to the fact that in the Russian Federation the assessment of the environmental component is expedient at the regional level, which is currently not given due attention due to the lack of adequate methodological tools.

The authors will further outline the possibilities and limitations of the assessment of the index of environmental perfor-mance at the regional level on the basis of the comparative analysis. We believe that the main advantage of the envi-ronmental performance index is the possibility of ranking the administrative-territorial units that make up the state.

\section{Results and Discussion}

We consider it important to note that the system of indicators proposed by Yale and Columbia universities is only suitable for inter-country comparison; its use for evaluation at the regional level requires more careful selection and adaptation of indicators, since many of them are inaccessible for comparison of the Russian Federation subjects. The following shortcomings of the indicated system of indicators can be identified: 1) the laboriousness of the analysis due to the need to handle the significant amount of statistical data in a number of areas; 2) the inability to analyze the numerical values of indicators in dynamics due to the above-mentioned circumstances (changes in the set of indicators, changes in the methodology for constructing the index).

The measurement of the environmental performance index at the regional level is advisable in connection with the fact that all subjects of the Russian Federation have a number of specific features, some of them are regions-donors, others - regions-recipients; some are labor-surplus, others are labor-defective, etc. We are aware that, perhaps, the indicator of the environmental performance index, measured at the national level, will have the better value than the value of the index of the environmental performance index in the industrial region specializing in, say, coal mining. But this value, even "negative" is extremely important, since it will testify either the imperfection of the environment protection and of citizens' health policy, or the long-term stagnation, or the environmental degradation in a number of parameters [7]. The point is that the fundamental degradation shifts in such important areas as "air quality", "water resources", "habitat biodiversity", "agriculture", etc., pose the great danger to the social and economic development of the state in the long term $[8,9]$.

As the researchers themselves admit, the methods for calculating the ecological performance index are not yet per-fect; therefore they undergo constant changes (Table 1). Despite the use of new technologies, such as satellite data or remote sensing, the continuing lack of comparable data for monitoring, in particular of freshwater quality, loss of spe-cies diversity, adaptation to climate change, waste management, indoor air quality, toxic chemicals, soil quality and degradation of agriculture, is observed. In the case of nitrogen balance, for example, the state can demonstrate both the nitrogen excess and its deficiency due to the soil-climatic differences. The national nitrogen balance indicator may not take into account these nuances. For the purpose of leveling this situation, we believe that 
regional indicators will illustrate more accurate and important data than national indicators [10].

Table 1. Indicators on the basis of which the environmental performance index is built

\begin{tabular}{|c|c|c|c|c|}
\hline $\begin{array}{l}\text { Group of } \\
\text { indicators }\end{array}$ & Indicators & 2012 & 2014 & 2016 \\
\hline \multicolumn{5}{|c|}{ Environmental health } \\
\hline \multirow[t]{2}{*}{ Health } & Infant mortality & + & + & - \\
\hline & Environmental health effects & - & - & + \\
\hline \multirow{5}{*}{$\begin{array}{l}\text { Air pollution, } \\
\text { affecting health }\end{array}$} & The presence of solid particles in the air & + & + & + \\
\hline & $\begin{array}{l}\text { Percentage of population exposed to } \\
\text { increased particulate matter }\end{array}$ & - & + & - \\
\hline & Indoor air pollution (mean impact) & + & + & + \\
\hline & Excess air pollution & - & - & + \\
\hline & Exposure to $\mathrm{NO}_{2}$ & - & - & + \\
\hline \multirow{2}{*}{$\begin{array}{l}\text { Water (effect on } \\
\text { human health) }\end{array}$} & Access to sanitation & + & + & + \\
\hline & Access to drinking water & + & + & + \\
\hline \multirow{2}{*}{$\begin{array}{l}\text { Air (effect on } \\
\text { the eco-system) }\end{array}$} & $\mathrm{SO}_{2}$ per capita & + & - & - \\
\hline & Ratio of $\mathrm{SO}_{2}$ to GDP & + & - & - \\
\hline \multicolumn{5}{|c|}{ Viability of the ecosystem } \\
\hline \multirow{2}{*}{$\begin{array}{l}\text { Water resources } \\
\text { (effect on the } \\
\text { ecosystem) }\end{array}$} & Change in water quality & + & + & - \\
\hline & Sewage water treatment & - & + & + \\
\hline \multirow[t]{6}{*}{ Biodiversity } & Habitat protection & + & + & - \\
\hline & $\begin{array}{l}\text { Terrestrial protected areas in the national } \\
\text { biome dimension }\end{array}$ & & & + \\
\hline & $\begin{array}{l}\text { Terrestrial protected areas as compared with } \\
\text { the global biomass mass }\end{array}$ & - & - & + \\
\hline & Protection of the national biome & + & + & + \\
\hline & Protection of the international biome & - & + & + \\
\hline & Marine protected areas & + & + & + \\
\hline \multirow[t]{4}{*}{ Agriculture } & Agricultural subsidies & + & + & - \\
\hline & Regulation of pesticides & + & + & - \\
\hline & Nitrogen balance & - & - & + \\
\hline & Nitrogen use efficiency & - & - & + \\
\hline \multirow[t]{3}{*}{ Forest } & Standing volume & + & - & - \\
\hline & Change in forest area & + & + & - \\
\hline & Loss of forest cover & + & - & + \\
\hline \multirow[t]{2}{*}{ Fishing } & Coastal shelf fishery & + & + & - \\
\hline & Exploitation of fish resources & + & + & + \\
\hline \multirow{5}{*}{$\begin{array}{l}\text { Climate Change } \\
\text { and Energy }\end{array}$} & $\mathrm{CO}_{2}$ per capita & + & + & - \\
\hline & $\mathrm{CO}_{2}$ emissonS to GDP & + & + & - \\
\hline & The trend of $\mathrm{CO}_{2}$ emissions per $\mathrm{kWh}$ & + & + & + \\
\hline & $\begin{array}{l}\text { Percentage of renewable electricity in total } \\
\text { generated electricity }\end{array}$ & + & - & - \\
\hline & The trend of carbon intensity & - & - & + \\
\hline \multicolumn{2}{|c|}{ Number of indicators } & 22 & 20 & 19 \\
\hline
\end{tabular}

Almost all the indicators reflected in Table 1 are currently inaccessible for analysis not only in the regional but also in the national context. The certain managerial impact can solve these problems. The use of advanced world experience can be useful for improving the environmental management. It is necessary to include - both at national and regional levels - all indices that are taken into account when forming the environmental performance index, and the use of such indicators should be accompanied by the accurate use of the 
assessment methodologies developed for it $[10,11]$. However, we consider the following as expedient:

1) to use the indicator used earlier - "Regulation of pesticides" in the group of indicators "Agriculture" instead of the indicators "Nitrogen balance" and "Nitrogen use efficiency", [12]. The use of this indicator is due to the fact that pesticides are one of the most dangerous types of chemical products for humans and the environment; therefore it is necessary to achieve the reasonable balance between the need to apply pesticides and the possible negative consequences of their use.

2) to use the indicator " $\mathrm{CO} 2$ per capita", which reflects the level of greenhouse gas emissions per capita in the group "Climate Change and Energy" in addition to the 2016 indicators. The relevance of this indicator is increasing due to the increase in the global average temperature on the planet and the continuing discussions about the need for mandatory use of $\mathrm{CO} 2$ capture and disposal technology [13].

The country / region receives points for each indicator. The sum of points depends on the position of the state within the range set by the worst country for this indicator (relative "zero" on the 100-point scale) and the desired goal (maximum 100 points). The desired goal is established on the basis of international treaties; standards defined by international organizations; professional conclusion, reflecting scientific consensus, other sources.

As for the method of determining the environmental performance index, we consider it necessary to note the following: at the initial stage, when applying the method of linear scaling to bring the values of indicators to the comparable type the administrative-territorial unit having the worst value of the indicator is given the value equal to zero, i.e. the estimate is initially underestimated. The main problem of the implementation of the valuation of indicators is that the reference value of the valued indicators is not taken into account. So, it is possible that when ranking the administrative-territorial units in the presence of the objectively unsatisfactory value of the indicator in the entire study group, one of the administrative-territorial units will receive the maximum estimate, and another unit - the minimal one, which does not correspond to reality. The way out of this situation is seen in the creation of the system of indicators that have the single unit of measurement or in the form of specific values per area unit, income unit, per capita.

\section{Conclusion}

It is interesting that the environmental performance index was originally developed for assessing the quality of life [14], achieving the sustainable development goals set out in the Millennium Declaration adopted by the United Nations in 2000, and later at the UN Summit of 2015, which formulated the goals of sustainable development for the period up to 2030, was used as the basic indicator of the "green economy", without losing its original meaning (used in calculating the human development index used to assess the quality of life). The foregoing predetermines the need for the indicative planning based on correlations with the system of EPI indicators.

\section{References}

1. C. Chess. J. Risk Res., 8(1), 63 (2005).

2. N. Ahmad, D. Jalaludin, N. Nazli. Social Responsibility Journal, 7(4), 540 (2011).

3. Environmental performance index. Yale and Columbian Universities in collaboration with World Economic Forum (Geneva and Joint Research Center of the EU, Ispra, 2012). 
4. I. Dias-Sardinha, L. Reijnders, P. Antunes. Environmental Quality Management, 12:2, 51 (2002).

5. F. Hernandez-Sancho, A. Picazo-Tadeo, E. Reig-Martinez. ERE, 15:4, 365 (2000).

6. N. Marchettini, V. Niccolucci, F. Pulselli and et al, ESPR, 14:4, 227 (2007).

7. S. Schmidheiny, F. Zorraquin. Financing change: the financial community, ecoefficiency, and sustainable de-velopment (MTP, New York, 1998).

8. R. Fish. Progress in Physical Geography, 35:5, 671 (2011).

9. U. Bititci, P. Garango. Int. J. Manag. Rev., 14, 305 (2012).

10. I. Chandrasekharan, R. Kumar, S. Raghunathan, S. Chandrasekaran. Current Science, 104:4, 435 (2013).

11. L. Thatte, H. Chande. Journal of Humanities and social science, 19:4, 1 (2014).

12. P. Tucker, K. Lewis, J. Skinner. Eco-management and auditing, 3, 9 (1996).

13. P. Narayan, S. Narayan. Energy Policy, 38:1, 661 (2010).

14. V. Constantiti, S. Monni. Ecological Economics, 64:4, 867 (2008). 